\title{
POSIBILIDADES Y BENEFICIOS DE UNA EXTENSION DEL ESPACIO DE INTEGRACION FRONTERIZO CON CHILE MAS ALLA DE TACNA Y ARICA
}

\author{
POSSIBILITIES AND BENEFITS OF AN EXTENSION OF THE BORDER \\ INTEGRATION AREA WITH CHILE BEYOND TACNA AND ARICA
}

Mijail Quispe Sandoval*

\section{RESUMEN}

El Gabinete Binacional Perú-Chile celebrado en julio de 2019 abrió la posibilidad de ampliar el espacio fronterizo entre los dos países, más allá del área consolidada formada por Tacna y Arica. La hipótesis a ser probada es que una mayor participación de las regiones contiguas de Moquegua y Tarapacá en foros bilaterales y una "visión ampliada de la región fronteriza binacional -sur peruano-norte chileno" promoverá beneficios mutuos para ambos países en áreas específicas como el turismo, la prevención de delitos transnacionales, las relaciones culturales, los asuntos migratorios, entre otros aspectos.

Palabras clave: Perú; Chile; Iquique, Tacna, Arica, Moquegua, frontera; integración; región fronteriza; movilidad; turismo; prácticas sociales; delitos transnacionales; migración, cultura.

\begin{abstract}
The Binational Peru-Chile Cabinet held in July 2019 laid the possibility of broadening the border space between the two countries, beyond the consolidated area shaped by Tacna and Arica. The hypothesis to be tested is that a greater involvement of the contiguous regions of Moquegua and Tarapaca in bilateral forums and an "expanded vision of the binational border region" -southern Peru-northern Chile, will promote mutual benefits for both countries, in specific areas like tourism, prevention of transnational crimes, cultural, academic and economic relations, among others.
\end{abstract}

Keywords: Peru; Chile; Iquique, Tacna, Arica, Moquegua, border; integration; border region; mobility; tourism; social practices; transnational crimes; migration, culture.

\footnotetext{
* Cónsul General del Perú en Iquique y Ministro Consejero en el Servicio Diplomático. Máster en Derecho Internacional Público por la Universidad de Nottingham (Reino Unido). Abogado por la Pontificia Universidad Católica del Perú. Se ha desempeñado como Profesor de Derecho Internacional Privado en ésta institución y de Derecho Internacional Público en el Ciclo de Preparación organizado por la Fundación Academia Diplomática del Perú. Antes de asumir funciones en Iquique, trabajó en la Dirección General de América en la coordinación de los Gabinetes Binacionales con Ecuador, Colombia y Bolivia.
} 


\section{INTRODUCCION}

El 10 de octubre de 2019 en la soleada bahía de Paracas, los Presidentes del Perú y Chile suscribieron como resultado del III Gabinete Binacional, una Declaración Presidencial que reflejaba a lo largo de sus 40 puntos la amplitud y riqueza de la agenda política, económicocomercial, cultural y de cooperación con nuestro vecino.

El documento como es usual en los gabinetes binacionales que el Perú ha establecido desde $2007^{1}$, fue acompañado de un Plan de Acción conteniendo 160 iniciativas distribuidas a su vez en 5 ejes temáticos: 1) asuntos sociales y cultura; 2) seguridad y defensa; 3) comercio exterior, inversiones, turismo y cooperación en ciencia y tecnología; 4) medio ambiente, desarrollo sostenible, asuntos energéticos y mineros, y finalmente 5) desarrollo, integración fronteriza y asuntos de infraestructura.

Uno de los aspectos relevantes acordados, contenido en el acápite 19 de la Declaración Presidencial, enuncia la posibilidad de ampliar en el futuro, un espacio de integración fronterizo, -actualmente conformado exclusivamente por Tacna y Arica-, a las regiones contiguas de los dos países. El texto señala que los Presidentes:

"Resaltaron el interés de Moquegua y Tarapacá de sumar esfuerzos para establecer a futuro un espacio de integración más amplio entre la zona sur del Perú y la zona norte de Chile, así como su incorporación como observadores en las subcomisiones de turismo y desarrollo económico del Comité de Integración y Desarrollo Fronterizo" (Declaración Presidencial-III Gabinete Binacional, 2019)

La redacción de este párrafo, si bien mesurada en sus expectativas, representará en su concreción futura un redimensionamiento de las relaciones transfronterizas especialmente en el tratamiento de diversas temáticas que son abordadas en los foros de diálogo bilateral existentes entre el Perú y Chile.

El objetivo principal del presente artículo es el de analizar una posible incorporación de las regiones de Moquegua y Tarapacá -región del norte de Chile donde residen más de 20 mil compatriotas ${ }^{2}$, en el tratamiento de aspectos específicos de la dinámica fronteriza. La hipótesis que se pretende demostrar es que un mayor involucramiento de dichas regiones en los foros bilaterales y en general, una "visión ampliada de la región fronteriza binacional" redundará en beneficio de ambos países y permitirá a su vez impulsar de manera más efectiva la integración entre el sur peruano y el norte chileno, en las áreas económico-comerciales, culturales, educativas, de seguridad, entre otras.

\footnotetext{
${ }^{1}$ El Perú realiza anualmente Gabinetes Binacionales -mecanismo del más alto nivel para el diálogo y la coordinación de políticas gubernamentales- con Chile, Colombia, Bolivia y Ecuador.

${ }^{2}$ El Registro de Connacionales del Consulado General del Perú en Iquique, actualizado a enero de 2020, arroja 19,830 connacionales inscritos, de lo que se desprende que la población peruana en Tarapacá -con su capital Iquique -excedería fácilmente las 21,000 personas.
} 


\section{REGIÓN FRONTERIZA BINACIONAL}

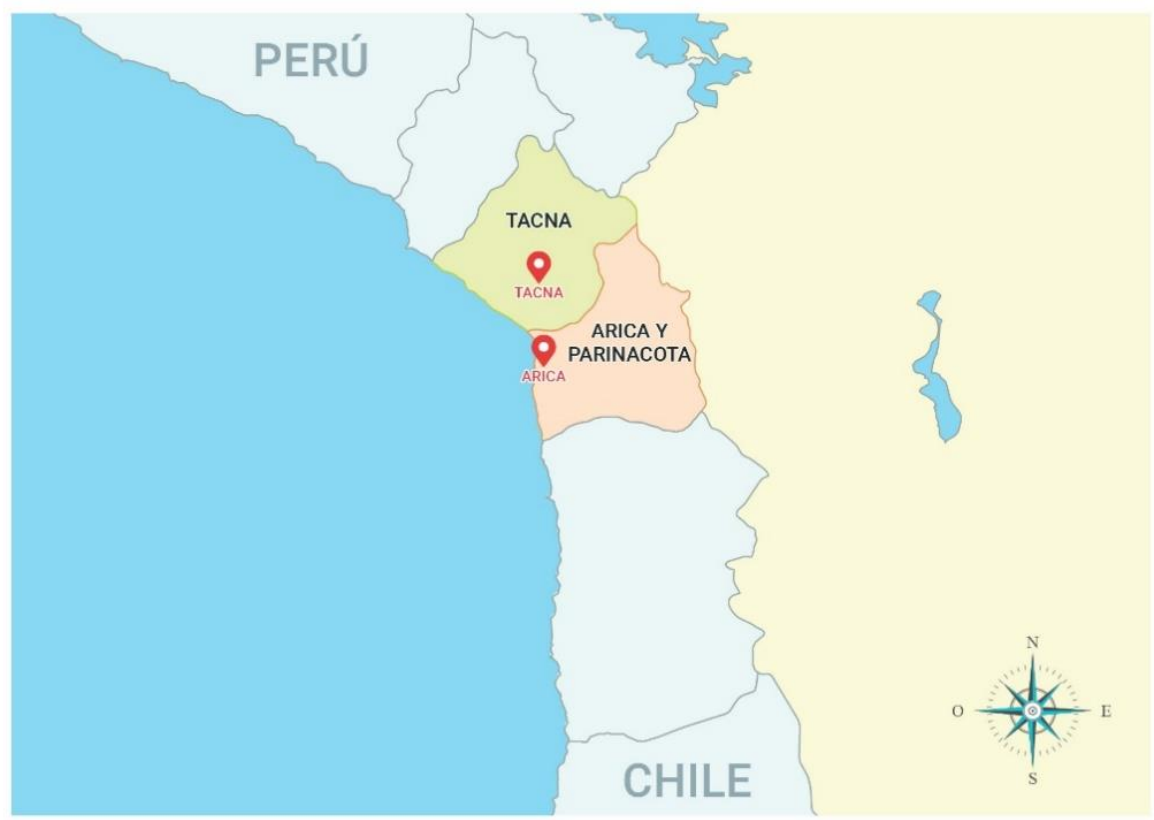

\section{REGIÓN FRONTERIZA BINACIONAL AMPLIADA}

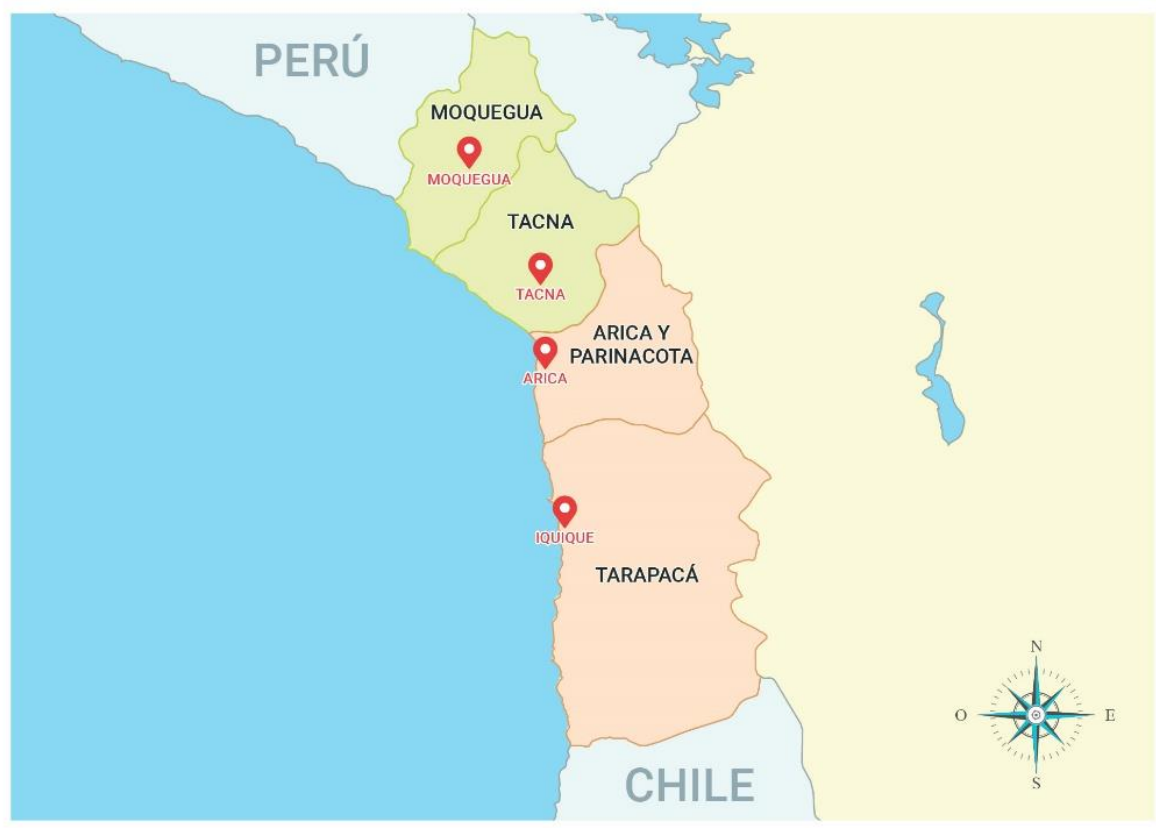




\section{MARCO CONCEPTUAL}

\subsection{LAS FRONTERAS}

El estudio de las relaciones transfronterizas en el ámbito de las relaciones internacionales ha atravesado un proceso evolutivo en las últimas décadas debido esencialmente al impulso dado por el fenómeno de la globalización y los procesos de integración a nivel regional y subregional. Desde una perspectiva académica, el estudio de las fronteras reviste en sí mismo una naturaleza compleja y multidisciplinaria. ${ }^{3}$ A partir de los años ochenta y con mayor énfasis en las dos últimas décadas, el estudio de las relaciones transfronterizas (border studies) ha experimentado un cambio notorio al pasar de una conceptualización de las fronteras como líneas divisorias que separan unidades territoriales (enfoque geopolítico clásico) hacia uno mucho más comprehensivo y acorde con los procesos de migraciones contemporáneos.

Desde esta perspectiva, las fronteras son visualizadas como espacios de interacción y encuentro, o como "fenómenos" o "productos sociales" (Derwich, 2018, 50). Estas se configuran, en buena cuenta como territorios de hibridación cultural (Dilla, 2018, 226). Pasamos entonces de una visión estática de la frontera, como línea divisoria hacia la configuración de un espacio que es la suma de procesos sociales, culturales o económicos en permanente recreación. En este contexto, "las fronteras actuales, además de límites geográficos, conforman espacios sociales, políticos, económicos y simbólicos, de diferenciación entre poblaciones nativas y extranjeras" (López Sala, 2010, 334).

No se trata, desde luego, del abandono de la conceptualización clásica de las fronteras. Esta visión permanecerá -o retornará cíclicamente- como lo reconfirma nuestra historia contemporánea. Así, eventos como la construcción de muros fronterizos en la administración Trump, o el propio Brexit ${ }^{4}$, son la palpable demostración que persistirán movimientos en sentido inverso, esto es, que expresen fronterización, restricción y clausura (Tapia, Gonzáles, 2014).

\subsection{REGIONES FRONTERIZA BINACIONALES}

Resulta pertinente para el objeto del presente estudio, examinar que naturaleza poseen las regiones fronterizas comunes, también consideradas en la nomenclatura de la Comunidad Andina de Naciones, como Zonas de Integración Fronteriza (ZIF). En primer término, habría que señalar que éstas, en tanto derivaciones de las fronteras, configuran un espacio donde las fuerzas sociales productivas y reproductivas se recrean de manera natural. De este modo involucran:

“...espacios de desarrollo de un conjunto de actividades al interior de cada Estado y que tiene a la frontera como un centro vital de referencia... dentro de ellas se hallan fuerzas sociales y relaciones de producción y de poder que funcionan en dependencia o con una cierta autonomía

\footnotetext{
${ }^{3}$ Dentro de éstas se puede mencionar a la Geografía, la Sociología, la Antropología, la Ciencia Política, la Economía y el Derecho Internacional.

${ }^{4}$ Es dable avizorar que la reciente pandemia del Covid19, cuyas catastróficas consecuencias aún son difíciles de mesurar en toda su magnitud, operará como una poderosa fuerza anti-migratoria y retardataria de los mecanismos de facilitación fronteriza en diversos países para los próximos años.
} 
respecto de otras realidades... es un espacio de vida que traspasa las líneas de separación y origina una integración entre los territorios colindantes." (Morales, 2010, p 187, 189-190).

Nótese que el rasgo distintivo que determina la existencia de una región fronteriza binacional no lo da la simple contigüidad del espacio geográfico respecto de la línea demarcatoria sino la presencia de fuerzas sociales y relaciones como resultado de la existencia de aquella. Este "espacio de vida" que refiere el autor resulta plenamente válido, como veremos más adelante, respecto de nuestra frontera sur. Asimismo, nos permitirá comprobar que el mismo, no abarca de manera exclusiva a Tacna y Arica, sino que irradia con apreciable fuerza a las regiones contiguas de uno y otro lado, a través de sinergias que dan cuenta de una dinámica recreada permanentemente en el espacio territorial de ambos países.

Dos conceptos adicionales tomados también de los estudios de las relaciones transfronterizas, nos serán útiles para el presente ensayo. Nos referimos a las denominadas "prácticas o flujos productivos y reproductivos" que desencadena la movilidad de personas, y que configuran, como señaláramos, elementos distintivos de la presencia de una región fronteriza binacional. En adelante, consideraremos como "prácticas socioespaciales productivas" a las conductas orientadas a la búsqueda de empleo en la zona de frontera del otro país, y de otro lado, como "prácticas sociales reproductivas" a aquellas que corresponden al ocio o recreación y a la búsqueda en el país vecino de determinados servicios como la salud, entre otros. (Tapia, Liberona, Contreras, 2017, 2)

Como veremos seguidamente, ambos tipos de prácticas sociales, las productivas y las reproductivas, están presentes de manera cotidiana en nuestra región fronteriza con Chile.

\section{LA REGION FRONTERIZA PERUANO-CHILENA}

Tradicionalmente, se ha asumido, desde un criterio exclusivamente geográfico, que el espacio fronterizo entre el Perú y Chile lo constituyen Tacna y Arica. Ciertamente, entre ambas jurisdicciones se ha gestado a lo largo de la historia y de manera aún más notoria en tiempos recientes, un espacio regional que involucra intercambios sociales, comerciales y demográficos. Examinemos algunos de ellos.

A través del paso Santa Rosa-Chacalluta circulan alrededor de 7 millones de personas anualmente y hasta 30 mil de manera diaria en las temporadas de verano. Resulta cotidiano apreciar los fines de semana largos bajo el pesado calor del mediodía, filas de autos repletos de turistas chilenos quienes viajan a Tacna por turismo (comercial, gastronómico y en no pocos casos por motivos de salud), o deciden emprender una ruta turística desde allí hacia las demás regiones del sur de nuestro país. Abona a favor de lo anterior, la natural empatía del poblador nortino hacia la música, el baile y la comida peruana, -para citar solo tres ejemplos concretoshechos que nos hablan de una conexión palpable y de la vitalidad de una vecindad que ha persistido a través del tiempo, sobreponiéndose aún a los dramáticos episodios que se desencadenaron durante el azaroso siglo XIX. ${ }^{5}$

\footnotetext{
${ }^{5}$ El rostro andino y aymara del norte chileno es un elemento adicional que coadyuvaría a que la natural "otredad" hacia el migrante y su cultura sea asumida con mayor empatía que en otras regiones del mismo país.
} 
El siguiente cuadro refleja el intensivo movimiento de circulación a través de Santa Rosa-Chacalluta los tres últimos años (ver cuadro No 1).

\section{CUADRO No. 1}

\begin{tabular}{|l|l|}
\hline \multicolumn{2}{|c|}{$\begin{array}{c}\text { MOVIMIENTO MIGRATORIO DE CIUDADANOS PERUANOS Y EXTRANJEROS POR LA FRONTERA ENTRE } \\
\text { PERÚ Y CHILE }\end{array}$} \\
\hline Año 2017 & 6.719 .885 \\
\hline Año 2018 & 7.062 .760 \\
\hline Año 2019 & 6.767 .004 \\
\hline
\end{tabular}

Fuente: Superintendencia Nacional de Migraciones

El paso Santa Rosa-Chacalluta, que opera desde el 2018 bajo un moderno sistema de control integrado ${ }^{6}$, es el segundo punto de entrada y salida del Perú, luego del Aeropuerto Internacional Jorge Chávez y la frontera terrestre más concurrida. Para el caso de Chile se trata, igualmente, de su frontera terrestre de mayor tránsito, si la comparamos con los pasos habilitados en sus fronteras con Bolivia y Argentina. ${ }^{7}$

De manera cotidiana, los flujos de movilidad se manifiestan a través del espacio regional, bien sea por razones de índole laboral -un caso interesante lo ofrecen los jornaleros peruanos que son contratados estacionalmente para laborar en los valles de Azapa y Lluta, principalmente en el cultivo de hortalizas-, o también el caso de nuestros migrantes de Tacna o Puno que intentan obtener trabajos eventuales en Arica, Iquique o Antofagasta, para luego retornar a sus ciudades de origen. Adicionalmente, puede apreciarse una movilidad típicamente de consumo (las visitas a las tradicionales ferias y mercadillos de Tacna de parte de turistas chilenos, por ejemplo), el denominado "turismo o movilidad por salud" que se desplaza masivamente desde Iquique y Arica hacia Tacna los fines de semana y que configura además un fenómeno aún poco estudiado a pesar de los beneficios que importa para Tacna ${ }^{8}$, etc. Todas estas relaciones sociales en ambas direcciones coexisten en un entramado de "prácticas socioespaciales", que determinan finalmente espacios comunes, interdependientes y transfronterizos (Tapia, Contreras, Liberona, 2017, 139).

Entonces, en la región fronteriza peruano-chilena podemos verificar-para aplicar dos conceptos introducidos en el acápite anterior- prácticas productivas (movilidad para obtener empleo o beneficio económico en general) y reproductivas (tendientes al aseguramiento

\footnotetext{
${ }^{6}$ El control integrado -de interés común para ambos países- es una demostración del elevado nivel entendimiento entre el Perú y Chile. Su impulso definitivo se dio como resultado del I Gabinete Binacional, celebrado en Lima, el 7 de julio de 2017.

${ }^{7}$ De allí que el cierre de fronteras establecido como consecuencia del Estado de Emergencia (DS No. 044-2020PCM) haya tenido en este caso un impacto mucho mayor que en las demás fronteras, pues ha significado una irrupción dramática en el modus vivendi de miles de personas.

${ }^{8}$ La movilidad por salud, uno de los principales motivos para cruzar desde el norte chileno hacia Tacna, es consecuencia de la asimetría -favorable a ésta última- en la oferta de servicios médicos respecto de Arica y Tarapacá. Las justificaciones de esta movilidad singular son variadas: un ahorro promedio de hasta 10 veces en precios de consulta, una mayor celeridad en la obtención de resultados de análisis clínicos e histológicos, y la percepción de un "trato más personal" en la relación médico-paciente. Un dato adicional resulta por demás elocuente, en la ciudad de Tacna existen al menos 72 centros de salud en comparación con los 21 existentes en Arica (Tapia, Liberona, Contreras, 2017).
} 
inmediato de algún servicio como salud, seguridad o recreación). Las primeras se expresan en mayor medida, en la dirección Perú-Chile, mientras que la segunda en sentido contrario, ChilePerú. Surge así un entramado vital y continuo que motiva la acertada reflexión del investigador Podestá Arzubiaga:

"Durante casi 130 años, las poblaciones de ambas regiones coexisten tranquilamente, testimoniando que sus estrategias de sobrevivencia y economías regionales se requieren mutuamente, que los ciclos productivos, sean de bonanza o crisis, afectan por igual a las dos regiones, éstas también aprovechan, en conjunto, las variaciones en los tipos de cambio que dinamizan uno u otro lado de la frontera....ariqueños y tacneños han sido, históricamente, cruzadores de fronteras, viajando permanentemente entre una y otra ciudad, por razones de comercio, recreación, salud, educación o de visitas familiares." (Podestá, 2011, 128)

\section{Foros bilaterales de integración fronteriza.-}

Desde una perspectiva institucional la relación bilateral en asuntos de frontera es abordada en el Comité de Integración y Desarrollo Fronterizo (CIDF), foro que opera desde el año 2011. Su antecedente inmediato es el Comité de Frontera Perú-Chile. En 2011, éste fue reformulado con el propósito que la visión administrativa en temas de frontera sea asistida por un enfoque de desarrollo socio-económico destinado a beneficiar las zonas fronterizas de los dos países. De este modo surgió la actual CIDF. Este foro contiene una compleja red de 3 Comisiones y 17 Subcomisiones las cuales abordan aspectos de interés común como la facilitación fronteriza, la infraestructura, el turismo, la educación y cultura, la trata de personas, el voluntariado juvenil, los temas de salud, medio ambiente, aspectos fito y zoosanitarios, etc. ${ }^{9}$

La pregunta que podríamos hacernos entonces es, si este espacio fronterizo binacional consolidado, institucionalizado y fácilmente reconocible conformado por Tacna y Arica, podría ser susceptible de una ampliación hacia las regiones contiguas de Moquegua y Tarapacá. ¿Podría ello llevarnos a acciones conjuntas más eficientes en términos de desarrollo socioeconómico e integración para las regiones de los dos países y en general, para un mejor tratamiento de la intensa temática de frontera?

Para responder a esta pregunta, nos abocaremos en primer término a delinear un breve perfil socio-económico de las regiones de Tacna y Moquegua y de otro lado, de Arica y Parinacota (XV Región) y Tarapacá (I Región). En los cuadros No. 2 y 3 se puede apreciar las características generales de las regiones mencionadas.

\section{CUADRO NO. 2}

\section{PERU}

\section{REGION TACNA}

\begin{tabular}{|l|l|l|l|}
\hline Superficie & $16,076 \mathrm{~km} 2$ & División política: & $\begin{array}{l}\text { Tacna, Candarave, } \\
\text { Jorge Basadre, Tarata }\end{array}$ \\
\hline
\end{tabular}

\footnotetext{
${ }^{9}$ Es pertinente dejar anotado que la CIDF es también un espacio de concertación transfronteriza en el que la alta política da cabida a los diversos actores y operadores regionales y locales que guardan relación con la dinámica de frontera.
} 


\begin{tabular}{|l|l|l|l|}
\hline $\begin{array}{l}\text { Población (Censo } \\
\text { 2017) }\end{array}$ & 341,838 habitantes & Clima: & $\begin{array}{l}\text { Desértico cálido. Frio } \\
\text { en zonas de cordillera }\end{array}$ \\
\hline PBI Regional & $\begin{array}{l}\text { US\$ 2.725 mil } \\
\text { millones }\end{array}$ & Exportaciones (2018): & US\$ 194.7 millones \\
\hline $\begin{array}{l}\text { Principales } \\
\text { actividades } \\
\text { económicas }\end{array}$ & $\begin{array}{l}\text { Minería (oro, } \\
\text { molibdeno, cobre) } \\
\text { agricultura, pesquería }\end{array}$ & $\begin{array}{l}\text { Principales mercados } \\
\text { de destino de las } \\
\text { exportaciones } \\
\text { regionales }\end{array}$ & $\begin{array}{l}\text { Estados Unidos, Chile, } \\
\text { Brasil, Ecuador }\end{array}$ \\
\hline
\end{tabular}

Fuentes: Ministerio de Comercio Exterior y Turismo-BCRP 2019

\section{REGION MOQUEGUA}

\begin{tabular}{|c|c|c|c|}
\hline Superficie & $15,734 \mathrm{~km} 2$ & División política: & $\begin{array}{l}\text { Provincias, } \quad \text { Mariscal } \\
\text { Nieto, General } \\
\text { Sánchez Cerro, Ilo }\end{array}$ \\
\hline $\begin{array}{l}\text { Población } \\
\text { 2017) }\end{array}$ & 226,068 habitantes & Clima & $\begin{array}{l}\text { Templado y seco, } \\
\text { subtropical y desértico. } \\
\text { Frío en zonas de } \\
\text { cordillera }\end{array}$ \\
\hline PBI Regional & $\begin{array}{ll}\text { US\$ } 2.657 & \text { mil } \\
\text { millones } & \end{array}$ & Exportaciones (2018): & $\begin{array}{l}\text { US\$ } 2.038 \quad \mathrm{mil} \\
\text { millones }\end{array}$ \\
\hline $\begin{array}{l}\text { Principales } \\
\text { actividades } \\
\text { económicas }\end{array}$ & $\begin{array}{lr}\text { Minería } & \text { (cobre, } \\
\text { molibdeno, } & \text { oro) } \\
\text { pesquería, agricultura. }\end{array}$ & $\begin{array}{ll}\text { Principales } & \text { mercados } \\
\text { de destino de las } \\
\text { exportaciones } \\
\text { regionales }\end{array}$ & $\begin{array}{l}\text { China, Italia, Brasil, } \\
\text { Japón, Chile }\end{array}$ \\
\hline
\end{tabular}

Fuentes: Ministerio de Comercio Exterior y Turismo-BCRP 2019

Algunas observaciones complementan la información contenida en el Cuadro No. 2

1- Moquegua y Tacna se encuentran entre las cinco regiones del Perú con mayores índices de competitividad (INCORE) ${ }^{10}$. Este índice incluye indicadores en materia de entorno económico, infraestructura, salud, educación, área laboral e institucional.

2- Existe una continuidad geográfica notoria, que explica además el perfil principalmente minero-exportador de ambas regiones. Los pesos económicos que mantienen, bastante similares en PBI Regional, y en porcentajes de participación a nivel del país, no demuestran asimetrías notorias.

3- Se trata en suma de regiones que contemplan indicadores socio-económicos relativamente superiores a otras jurisdicciones del país y que podrían dada su vecindad complementarse y apoyarse mutuamente en el tratamiento de determinadas temáticas de frontera.

Evaluamos ahora el cuadro No. 3 que ejemplifica el perfil de las regiones Arica y Tarapacá.

\section{CUADRO No. 3}

\section{CHILE}

\footnotetext{
10 Índice de Competitividad Regional. Reporte INCORE 2019. Instituto Peruano de Economía.
} 


\section{REGION ARICA Y PARINACOTA}

\begin{tabular}{|l|l|l|l|}
\hline Superficie & $16,873 \mathrm{~km} 2$ & División política: & $\begin{array}{l}\text { Provincias de Arica y } \\
\text { de Parinacota }\end{array}$ \\
\hline $\begin{array}{l}\text { Población (Censo } \\
\text { 2017) }\end{array}$ & 224,548 habitantes & Clima & $\begin{array}{l}\text { Desértico, escasez } \\
\text { hídrica. Presencia de } \\
\text { ríos en la zona del } \\
\text { lltiplano }\end{array}$ \\
\hline PBI Regional & $\begin{array}{l}\text { US\$ 1.305 mil } \\
\text { millones }\end{array}$ & Exportaciones (2018) & US\$ 161 millones \\
\hline $\begin{array}{l}\text { Principales actividades } \\
\text { económicas }\end{array}$ & $\begin{array}{l}\text { Transportes, } \\
\text { construcción, servicios } \\
\text { financieros }\end{array}$ & $\begin{array}{l}\text { Principales mercados } \\
\text { de destino de de } \\
\text { exportaciones }\end{array}$ & $\begin{array}{l}\text { EEUU, Holanda, } \\
\text { Brasil, China }\end{array}$ \\
\hline NUMERO ESTIMADO DE CONNACIONALES: 12,000 \\
\hline
\end{tabular}

Fuente ODEPA Chile, 2019.

\section{REGION TARAPACA}

\begin{tabular}{|l|l|l|l|}
\hline Superficie & $42,225 \mathrm{~km} 2$ & División política: & $\begin{array}{l}\text { Provincias de Iquique y } \\
\text { Tamarugal }\end{array}$ \\
\hline $\begin{array}{l}\text { Población (Censo } \\
\text { 2017) }\end{array}$ & 330.558 habitantes & Clima & $\begin{array}{l}\text { Desértico, ausencia de } \\
\text { precipitaciones }\end{array}$ \\
\hline PBI Regional & $\begin{array}{l}\text { US\$ 5.020 mil } \\
\text { millones }\end{array}$ & Exportaciones (2018) & US \$3.892 millones \\
\hline $\begin{array}{l}\text { Principales actividades } \\
\text { económicas }\end{array}$ & $\begin{array}{l}\text { Minería, comercio, } \\
\text { turismo, servicios } \\
\text { financieros }\end{array}$ & $\begin{array}{l}\text { Principales mercados } \\
\text { de destino de } \\
\text { exportaciones }\end{array}$ & $\begin{array}{l}\text { China, } \\
\text { Holanda, Italia, } \\
\text { Noruega }\end{array}$ \\
\hline NUMERO ESTIMADO DE CONNACIONALES RESIDENTES: 21.000 \\
\hline
\end{tabular}

Fuente ODEPA Chile, 2019.

Algunas observaciones al respecto:

a) Tarapacá y más precisamente, su capital Iquique, se encuentra a solo 310 kilómetros de Arica y a 366 kilómetros de Tacna. En cambio, la distancia que la separa de Santiago, es varias veces mayor; casi 1800 kilómetros, y más de 20 horas en auto. Su vinculación con la frontera peruano-chilena es tan natural por la vecindad geográfica, como evidente su condición periférica respecto de Santiago, problematizada por el centralismo que aqueja a nuestros países desde tiempos históricos.

b) Demográficamente, Tarapacá tiene casi $50 \%$ más de población que Arica. Asimismo, en cuanto a superficie, Tarapacá triplica aproximadamente el tamaño de aquella.

c) La minería existente en Tarapacá genera una diferencia comparativa notable en el PBI Regional de ésta, casi cinco veces superior al de Arica. Puede señalarse, asimismo, que gracias a ZOFRI (Zona Franca de Iquique creada en 1976 y cuya vigencia se extenderá hasta 2030) y también debido a la red de servicios comerciales complementarios (la venta de autos es la más 
emblemática), Tarapacá ha logrado diferenciarse en las tres últimas décadas de Arica al presentar un perfil minero, productor y más industrializado. ${ }^{11}$

d) La situación descrita explica que Tarapacá y en especial Iquique, cobije casi el doble de connacionales que Arica. ${ }^{12}$, aunque ciertamente es necesario precisar que la composición poblacional de compatriotas en Arica incluye a quienes se desplazan desde Tacna, diariamente o por periodos muy cortos. En todo caso, la demanda de servicios que presenta Iquique respecto del carácter más "consumidor" de Arica abona a favor de la diferencia anotada. De hecho, Iquique, es la segunda ciudad de Chile luego de Santiago, con el mayor número de connacionales residentes ${ }^{13}$.

\section{VENTAJAS DE UNA ZONA DE INTEGRACION FRONTERIZA AMPLIADA A LA LUZ DE TRES CASOS ESPECIFICOS}

A fin de demostrar la hipótesis del presente estudio, examinaremos a continuación tres áreas de muy diversa naturaleza entre sí, en las cuales la ampliación de un espacio de integración fronterizo más allá del tradicional eje Tacna-Arica resultaría beneficiosa para ambos países.

\section{CASO 1: Moquegua y la ampliación de la ruta turística procedente del norte de Chile}

La industria turística en el Perú, como consecuencia de la pandemia enfrenta un panorama volátil y extremadamente complejo. Una vez que se reinicie paulatinamente la apertura de las fronteras y se retome la actividad turística será necesario aplicar medidas estratégicas de emergencia y recuperar los flujos turísticos pre-covid.

En este orden de ideas, es una verdad confirmada anualmente por las estadísticas, que Chile es el principal país emisor de turistas con destino al Perú, representando el $26 \%$ del total de arribos internacionales (Reporte Promperú 2019). Considerando la dinámica de nuestra frontera terrestre es previsible entonces que un porcentaje significativo de ciudadanos chilenos que visitan el sur peruano tenga como motivo principal el turismo. Un estudio realizado en 2017 por la Universidad Arturo Prat de Tarapacá develó que esa fue la motivación más importante para un $36.3 \%$ de chilenos. ${ }^{14}$. Un dato adicional de dicha encuesta mostró que un $74,4 \%$ lo hizo en un auto propio, con la flexibilidad que ello importa en términos de desplazamiento y tiempos de visita.

Ahora bien, considerando que existe ya una ruta turística consolidada hacia Tacna, la proximidad geográfica de Moquegua (cuya capital está ubicada a sólo dos horas de la Ciudad Heroica) y la variedad de atractivos que dicha región ofrece, justifica que se realicen los esfuerzos necesarios para promover naturalmente una extensión de la ruta del turista extranjero.

\footnotetext{
${ }^{11}$ El aporte de Zofri al norte a Arica y Tarapacá es significativo. Solo en el ejercicio 2019 ambas regiones percibieron \$ 5470 millones de pesos, equivalente aproximadamente a US\$ 6’800,000 (ZOFRI, Ejercicio 2019).

${ }^{12}$ Este dato se reconfirma en el hecho que el Consulado General en Iquique realiza más de 150 atenciones diarias y siendo una ciudad del interior, es superada en este rubro en Sudamérica solamente por dos capitales Santiago y Buenos Aires.

${ }^{13}$ La tercera ciudad en número de compatriotas es Antofagasta, en la II Región, con una comunidad de aproximadamente 16,000 connacionales. Tanto Iquique como Antofagasta se encuentran bajo la jurisdicción del Consulado General del Perú en Iquique.

${ }^{14}$ Encuesta UNAP-FONDECYT No. 1150123.
} 
La oferta que ofrece la región Moquegua al respecto es muy diversificada. Baste mencionar por ejemplo: las playas en Ilo, los valles y campiñas de clima templado en el interior; la ruta gastronómica de raíces mestizas y fuerte componente andino; la importante producción pisquera y vitivinícola con más de veinte bodegas de uvas destinadas a nuestro destilado ${ }^{15}$, sitios prehispánicos de las culturas Tiawanaku y Wari, una arquitectura colonial y republicana conservada en la hermosa ciudad de Moquegua, entre otros aspectos.

Consecuentemente, una visión ampliada de la región fronteriza permitiría involucrar a la región Moquegua en todos aquellos aspectos de tratamiento bilateral que tengan relación con el turismo (seguridad del turista, promoción de actividades o experiencias para el visitante, beneficios tributarios, etc). La propuesta de establecer una Ruta Turística del Sur ha sido ya planteada por las autoridades regionales de Moquegua, así como también su interés en participar en los mecanismos de diálogo fronterizo en temas de turismo, los que hasta el momento, como ha sido mencionado, involucran exclusivamente a Tacna y Arica. ${ }^{16}$

No deja de resultar relevante el hecho que desde el lado chileno, similar interés respecto de Tarapacá haya sido manifestado por las autoridades de turismo (Sernatur) de dicha región ${ }^{17}$. La propuesta de establecer, entonces, un amplio circuito turístico entre el norte de Chile y el sur del Perú para el turista sudamericano o europeo generaría beneficios mutuos para las regiones de los dos países y merece ser estudiada con detenimiento.

\section{CASO 2: El Delito de Trata de Personas: una visión más integral sobre este problema.-}

De acuerdo con el Plan Nacional contra la Trata de Personas 2017-2021, el Perú es considerado como un país de destino, origen y tránsito de víctimas de trata. En este marco, se considera prioritaria la prevención, combate y protección de las personas que han sufrido los perniciosos efectos de este execrable delito. Las características, modalidades, rutas y magnitud del mismo son abordadas a partir de las denuncias presentadas al Ministerio Público y la Policía Nacional. ${ }^{18}$ En el ámbito del Derecho Internacional, el Perú -así como Chile- son Estados Parte de la Convención contra la Delincuencia Organizada Transnacional, más conocida como la "Convención de Palermo", así como de sus Protocolos Complementarios.

El Plan Nacional contra la Trata de Personas enfatiza que siendo éste un delito que traspasa las fronteras, la articulación de instrumentos jurídicos internacionales y las acciones conjuntas para perseguir las redes de criminalidad organizada resultan sumamente importantes. Bajo estas premisas el reforzamiento de la cooperación entre los Estados en las regiones de frontera forma parte ineludible de los planes de acción que coordina el Perú con sus vecinos.

\footnotetext{
${ }^{15}$ Entre estas puede mencionarse: Biondi, Atencio, Parras y Reyes, Don Camilo y El Mocho.

${ }^{16}$ Un antecedente es el Acta de la IV Reunión del Comité de Integración y Desarrollo Fronterizo Perú-Chile (2015) en el que se registra el interés de Moquegua de incorporarse formalmente a la Subcomisión de Turismo de dicho mecanismo bilateral. En el año 2017, el Gobierno Regional de Moquegua invitó a los Cónsules Generales del Perú en Arica e Iquique para coordinar esfuerzos en función de esta ampliación de la ruta turística.

${ }^{17}$ La Región Tarapacá, ubicada a solo 4 horas de la frontera con Perú presenta atractivos importantes como ZOFRI (turismo de consumo y compras menores), costa y playas (las que usualmente reciben a turistas argentinos, bolivianos y paraguayos), turismo de aventura en la zona de cordillera, las salitreras de Humberstone y Santa Laura, entre otros.

${ }^{18}$ Decreto Supremo que aprueba el Plan Nacional contra la Trata de Personas 2017-2021. DS Nº 017-2017-IN. Diario Oficial El Peruano.
} 
Para el caso de nuestra frontera sur y como resultado del I Gabinete Binacional, los cancilleres del Perú y Chile suscribieron el "Acuerdo para fortalecer la Lucha contra la Trata de Personas, el Tráfico Ilícito de Migrantes y los delitos conexos”. El artículo V, parágrafo (a 2) del Acuerdo antes mencionado señala lo siguiente:

Artículo V.- Ámbito de Cooperación. La Comisión de Implementación y Monitoreo Binacional coordinará actividades, compromisos y resultados en los siguientes campos:

En materia de Trata de Personas

Prevención contra el Delito de Trata de Personas: (a2 ) Realizar acciones de prevención de la trata de personas principalmente en las zonas fronterizas de ambos Estados en cooperación con entidades estatales, organismos internacionales, organizaciones no gubernamentales, gremios profesionales y empresariales y otros integrantes de la sociedad civil con el objeto de hacer más eficaz la prevención de este delito.

Como refiere el texto, las zonas fronterizas de ambos países resultan "áreas territoriales preferenciales" para ejecutar acciones de prevención y concientización sobre la gravedad de este delito. Una de estas acciones es, ciertamente, la de desplegar campañas con contenidos comunicacionales de sensibilización y cambio de patrones de tolerancia respecto de la trata y el tráfico de migrantes.

La pregunta que podemos plantearnos es, entonces, si no sería más conveniente abordar un problema altamente complejo como éste a partir de una visión "ampliada" de la región fronteriza, y no circunscrita exclusivamente al eje Tacna-Arica, como se maneja actualmente en la Subcomisión de Trata, sub-órgano del Comité de Integración y Desarrollo Fronterizo Perú-Chile.

Algunas consideraciones al respecto nos permiten plantear una respuesta.

Para el caso del Perú, el Plan Nacional contra la Trata de Personas 2017-2021 refiere que una de las rutas internacionales seguidas por las redes delictivas -la denominada Costa Sur-, involucra a Arequipa, Moquegua y Tacna.

Desde el lado chileno, resulta pertinente mencionar que en 2019 diversos operativos policiales de la BITRAP (Brigada local Investigadora contra la Trata de Personas-Región Tarapacá) detectaron redes de trata con fines de prostitución, que habían traspasado por vía terrestre las fronteras de Colombia, Perú y posteriormente arribado a Chile. Otros casos similares, publicitados por los medios de comunicación en el norte de este país, se añadieron en los primeros meses de 2020. En todos ellos se verificó que el espacio Tacna-Arica fue solo parte de rutas delictivas más extensas que finalmente terminaron trasladando a sus víctimas a ciudades de mayor peso económico e industrial como Iquique y Antofagasta, lugares donde finalmente estas organizaciones fueron detectadas y capturadas.

Una propuesta sería entonces aplicar esta "ampliación de la región fronteriza binacional" en el tratamiento de este delicado tema, incorporando en los foros bilaterales pertinentes a operadores de justicia como jueces y fiscales, autoridades policiales de las regiones contiguas a Tacna y Arica y al propio Consulado General en Iquique para así lograr políticas mucho más efectivas en la prevención, combate y sanción de este delito. En otros términos, una ampliación del espacio de integración fronterizo generaría para efectos prácticos un tratamiento más eficaz al problema de la trata de personas como delito de naturaleza transnacional. 


\section{CASO 3: Asuntos migratorios y presencia social y cultural peruana en el norte de Chile}

Ha sido señalado en nuestro marco conceptual que los flujos de movilidad y las prácticas socio-espaciales productivas y reproductivas son elementos distintivos para la configuración de una región transfronteriza binacional. Ahora bien, gran parte del tránsito hacia Tacna, y en general al sur peruano, está constituido tanto por tarapaqueños que cruzan Santa $\operatorname{Rosa}^{19}$, como por peruanos residentes en Iquique que desean visitar a sus familias o realizar algunas compras en el sur de nuestro país. En dirección inversa, los compatriotas de Tacna, Moquegua, Puno y otros lugares, han preferido asentarse de manera preferente en Iquique por las ventajas económicas que aquella ofrece y que fueran detalladas anteriormente.

En materia migratoria, debe decirse que tras la ejecución del Proceso Extraordinario de Regularización Migratoria emprendido por Chile en 2018, la región de Tarapacá fue la segunda a nivel nacional con mayor número de migrantes inscritos, luego de Santiago ${ }^{20}$. Este hecho se replicó respecto de los compatriotas que se encontraban en condición de irregularidad. Los elementos anotados nos dan una idea de la relevancia de mantener una visión integral del norte de Chile como polo de atracción de nuestros migrantes.

Resulta obvio en consecuencia que, con relación a nuestra comunidad de compatriotas, el norte de Chile (Arica y Tarapacá) deberían ser abordados como una unidad, y sus respectivas capitales (Arica e Iquique) como epicentros de movimientos migratorios, con similar nivel de importancia para efecto del tratamiento de esta temática en los foros bilaterales de frontera.

Concluimos con algunas observaciones respecto a los asuntos culturales. La presencia peruana, aunque ciertamente histórica en sus orígenes, le ha dado a Tarapacá y en especial a Iquique, una fisonomía particular. Esta influencia es perceptible a ojos del visitante común. La plaza principal de la ciudad se encuentra adornada por la hermosa "Torre del Reloj" construida con elementos góticos y mudéjares, inaugurada en 1878 sólo un año antes del inicio de la Guerra del Pacífico. Caminando por el centro histórico de Iquique, el visitante se encontrará con la espléndida construcción neoclásica de la "Casa Billinghurst", sede del Consulado General del Perú que data de 1886 y fuera propiedad del ex-Presidente, de origen tarapaqueño. En su Sala Cultural, situada en el primer piso, un abarrotado público de peruanos y chilenos disfruta por igual de conciertos, recitales literarios, presentaciones de danza o exposiciones gastronómicas. $^{21}$

Otros elementos más se añaden a esta "hibridación cultural" de la que nos hablaba Dilla anteriormente y que se manifiestan en Iquique de manera cotidiana. Los festivales de música peruana que congregan a miles de iquiqueños, el emprendedurismo de compatriotas con historias personales de éxito, la positiva percepción que se tiene de la comunidad peruana en su conjunto como una colectividad laboriosa y comprometida, todos estos elementos son testimonios elocuentes de una presencia social y cultural peruana importante en Iquique. De allí que las actividades de promoción e intercambio cultural que se gestionen en el futuro en los foros bilaterales de frontera, deberían considerar también a Iquique y su numerosa

\footnotetext{
${ }^{19}$ Más de 15 empresas de autobuses recorren diariamente la ruta Iquique-Arica. Gran parte de los pasajeros pasan luego al Perú y retornan al día siguiente o al término del fin de semana.

${ }^{20}$ Nota de Prensa del Ministerio del Interior y Seguridad Pública de Chile (24 de julio de 2018).

${ }^{21}$ La Sala Cultural Billinghurst, abierta al público en 2017, ha pasado a incorporarse al circuito cultural de Iquique con un calendario de actividades mensual que incluye música, danza, historia, gastronomía, entre otras actividades.
} 
comunidad de compatriotas, reiterándose lo dicho en el sentido de mantener una visión unitaria del norte chileno.

Finalmente, y en el mismo orden de ideas, los intercambios académicos entre universidades e instituciones técnicas de Tacna y Arica -que ya se vienen ejecutando-, podrían redimensionarse con mejores resultados objetivos, si convocáramos a más regiones del sur del Perú y el norte de Chile. La proximidad geográfica - que reduciría costos- podría ser aprovechada entonces para promover encuentros científicos de frontera (como los ECI que se desarrollan exitosamente de manera semestral), coordinados con Concytec, y el apoyo de los Consulados en Arica e Iquique, las Oficinas Descentralizadas de Cancillería en Tacna y Arequipa, y otras instituciones.

\section{CONCLUSIONES}

1. El Gabinete Binacional Perú-Chile celebrado en julio de 2019 abrió la posibilidad de extender formalmente el espacio fronterizo entre ambos países, más allá del área ya consolidada conformada Tacna y Arica. Resulta pertinente evaluar si tal ampliación resulta conveniente no solo para los intereses de desarrollo socio-económico de las regiones contiguas de Moquegua y Tarapacá sino también, en función de un tratamiento más integral del sur peruano en su vinculación con el norte chileno.

2. El estudio de las relaciones transfronterizas (border studies) aporta elementos conceptuales y metodológicos útiles para una mejor comprensión de nuestra frontera con Chile, como espacio privilegiado en el cual se desarrolla un entramado de prácticas cotidianas socioespaciales productivas y reproductivas, derivadas de la intensidad del movimiento migratorio que se recrea allí de manera permanente.

3. Nuestra frontera sur ha modelado formas de circulación que no se restringen al espacio Tacna-Arica sino que irradian plenamente a las regiones contiguas de uno y otro lado, involucrándolas de manera natural en los fenómenos socio-culturales que allí se producen. De allí que desde la perspectiva de nuestra política exterior en materia de desarrollo fronterizo, sea necesario tomar en cuenta esta realidad a fin que los foros y espacios de discusión diplomáticopolíticos, económicos, comerciales, culturales y académicos asuman esta visión ampliada de la región fronteriza binacional.

4. Las regiones de Tacna y Moquegua comparten de acuerdo al perfil socio-económico elaborado en este ensayo, características que pueden coadyuvar a una complementariedad en el abordaje de determinadas temáticas de frontera. Uno de los aspectos por los que esta última región ha manifestado su interés es el del turismo, es decir, en que se promueva una extensión de la ruta turística que cotidianamente se desplaza desde el norte de Chile hasta Tacna. Una visión ampliada de la región fronteriza permitiría posibilitaría involucrar a Moquegua activamente en todos aquellos aspectos de tratamiento bilateral que tengan relación con el turismo (seguridad del turista, promoción de actividades, beneficios tributarios, etc.).

5. Otras áreas en materia de seguridad, como el de la prevención y combate del delito de trata de personas requiere igualmente una visión integral de la zona de frontera, hecho que se traduciría en políticas más eficaces para el tratamiento de este delicado problema.

6. Es relevante apreciar que, por el lado chileno, el peso económico de la región de Tarapacá y su perfil minero y de mayor industrialización respecto de Arica y Parinacota la ha convertido en un foco de atracción para la migración peruana que se asienta en el norte de Chile. Por tanto, 
desde la perspectiva de nuestra numerosa comunidad en Iquique, se requiere involucrar al Consulado General del Perú en esa ciudad, en los asuntos migratorios que se discutan en los foros bilaterales correspondientes.

7. Finalmente, las vinculaciones históricas, culturales y sociales abonan para una visión unitaria del norte del país vecino -que incluye ciertamente a Arica e Iquique por igual-, y que permitirán avanzar en la promoción de políticas binacionales más eficaces en términos de integración y desarrollo.

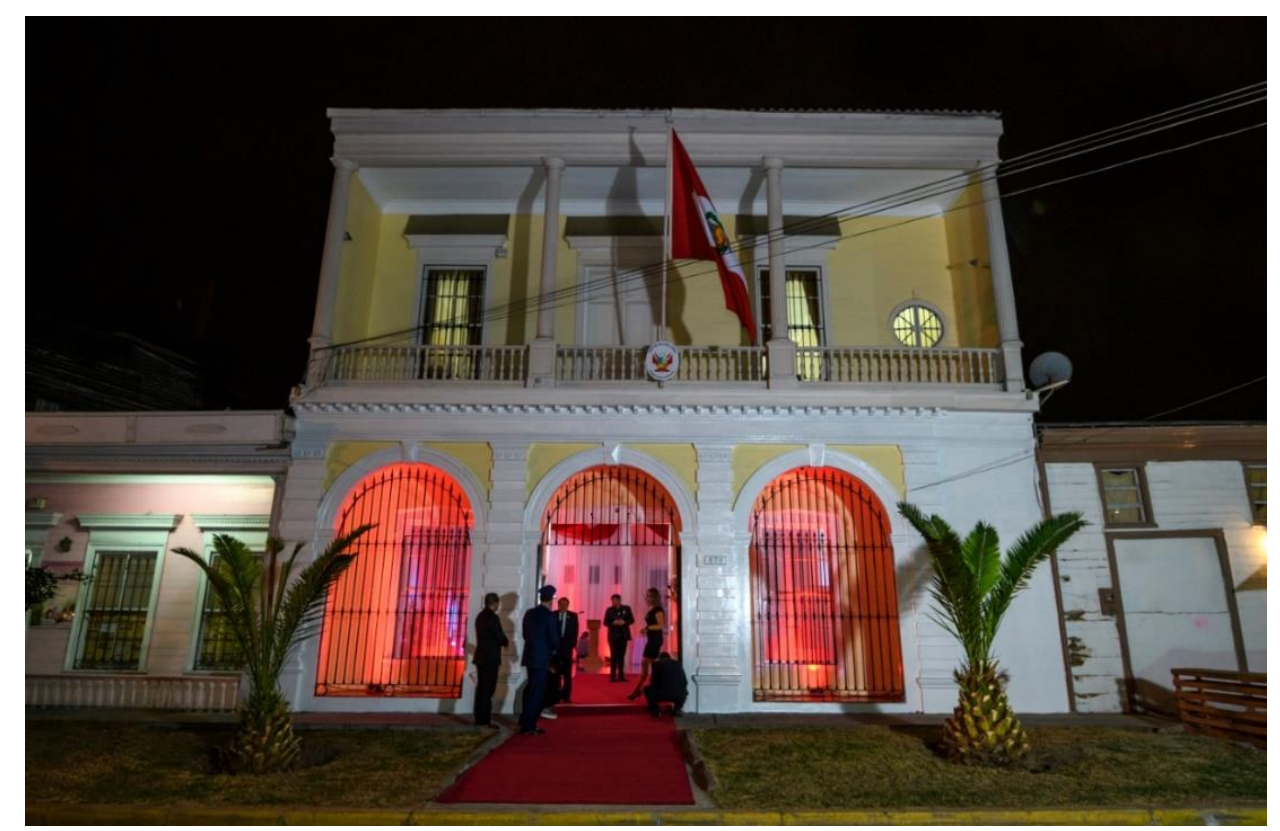

\section{Casa Billinghurst (1886) Sede del Consulado General del Perú en Iquique}

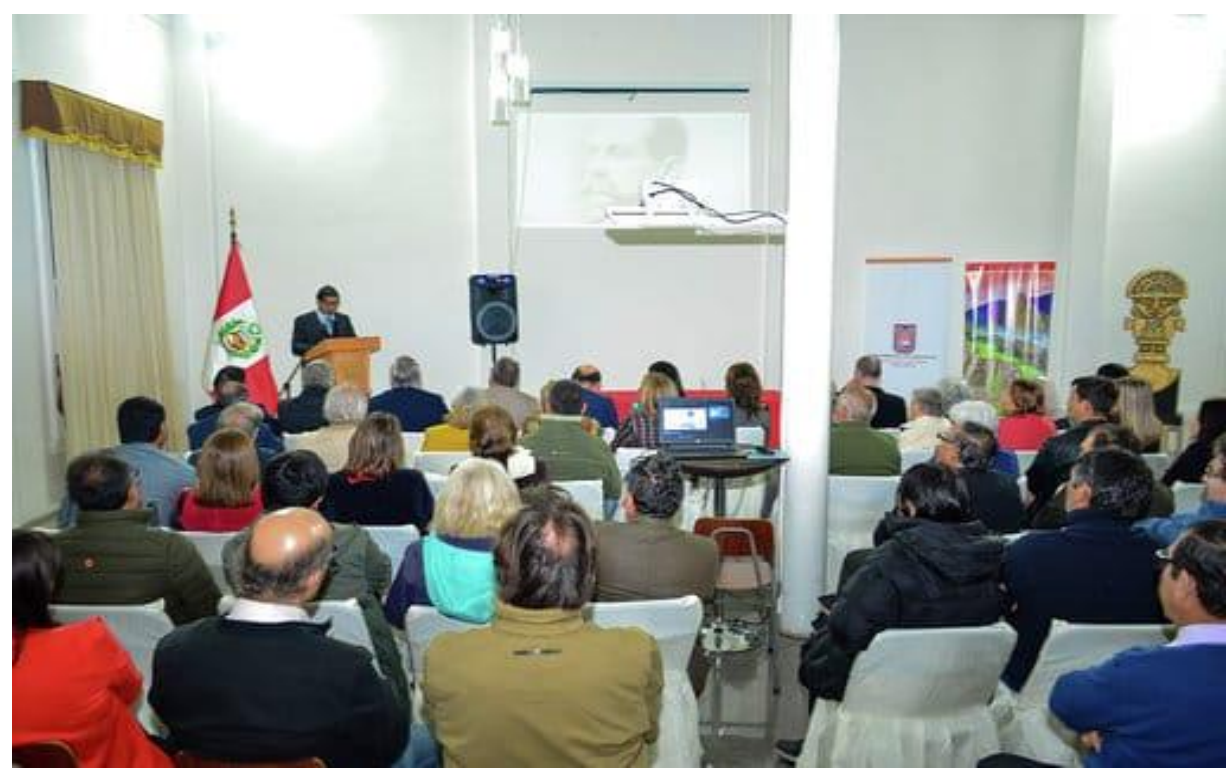

Conferencia en el marco de las actividades del Bicentenario -Casa Billinghurst- 


\section{BIBLIOGRAFIA}

- Álvarez, Camila. Diciembre 2019, Comité de Integración y Desarrollo Fronterizo Perú-Chile: aproximaciones al mundo social y empresarial en torno a la frontera. Revista Sí Somos Americanos. Instituto de Estudios Internacionales, Universidad Arturo Prat. Iquique, Volumen 19 No 2.

- Banco Central de Reserva del Perú (BCRP). Moquegua. Diciembre de 2018. Síntesis de Actividad Económica.

- Banco Central de Reserva del Perú (BCRP). Tacna. Diciembre de 2018. Síntesis de Actividad Económica.

-Boletín Oficial. Normas Legales El Peruano. Ediciones varias.

- Derwich, Karol. 2018. Fronteras como categoría social. La perspectiva teórica de las fronteras en el siglo XXI. Anuario Latinoamericano de Ciencias Públicas y Relaciones Internacionales. Krakovia Vol. 6.

- Dilla, Haroldo. 2018. Arica entre tres fronteras. Estudios atacameños. Instituto de Arqueología y Antropología de la Universidad Católica del Norte, San Pedro de Atacama. No. 57.

- Instituto Peruano de Economía (IPE). 2019. Índice de Competitividad Regional. Reporte INCORE.

- Jonhson, C., R. Jones, A. Paasi, L. Amoore, otros. 2011. Interventions on rethinking 'the border' in border studies. Political Geography 30: 61-69.

- MINCETUR. Reporte de Comercio Moquegua. 2019. Documentos Estadísticas y Publicaciones.

- MINCETUR Reporte de Comercio Tacna. 2019. Documentos Estadísticas y Publicaciones

- Morales, A. 2010. Desentrañando fronteras y sus movimientos transnacionales entre pequeños Estados. Una aproximación desde la frontera Nicaragua-Costa Rica. In Anguiano, M. E. y López, A. M. (Eds.), Migraciones y frontera. Nuevos contornos para la movilidad internacional (pp. 185-224). Barcelona. Icaria.

- Podestá, Juan. 2011. Regiones fronterizas y flujos culturales. La peruanidad en la región chilena. Revista Universum. Talca. No. 26. Vol 1.

- Tapia, Marcela-Liberona, Nanette-Contreras, Yasna. Mayo, 2017. El surgimiento de un territorio circulatorio en la frontera chileno-peruana: estudio de las practicas socio-espaciales fronterizas. Revista de Geografía Norte Grande. Santiago de Chile. 
- Tapia, Marcela. Liberona-Nanette-Contreras, Yasna. Setiembre, 2017. Movilidades y practicas socioespaciales fronterizas entre Arica y Tacna. Del sentido de frontera a la transfrontericidad entre ciudades. Dialogo Andino No. 54. Arica.

-Tapia, Marcela-González, Adriana (compiladores).2014. Regiones Fronterizas: Migración y los desafíos para los Estados nacionales latinoamericanos. Ril Editores. Santiago de Chile. 